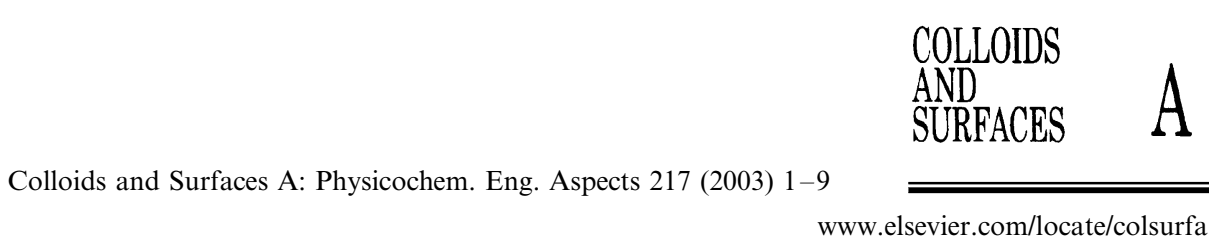

www.elsevier.com/locate/colsurfa

\title{
The iron status in colloidal matter from the Rio Negro, Brasil
}

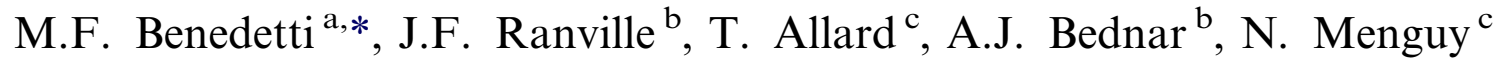 \\ a Laboratoire de Géochimie et Métallogénie, UMR CNRS 7047, Université Pierre et Marie Curie, Boite 124, 4 Place Jussieu, 75252 Paris \\ Cedex 05, France \\ ${ }^{\mathrm{b}}$ Department of Chemistry and Geochemistry, Colorado School of Mines, Golden, CO 80401, USA \\ ${ }^{\mathrm{c}}$ Laboratoire de Minéralogie-Cristallographie UMR CNRS 7590, Université Pierre et Marie Curie, Boite 115, 4, place Jussieu, 75252 \\ Paris Cedex 05, France
}

\begin{abstract}
Colloidal and particulate natural organic matter was size-fractionated and concentrated from the Rio Negro river using tangential-flow filtration (TFF). Flow field-flow fractionation (F-FFF), with UV absorbance detection (UVA), was used to investigate the molecular weight distributions of the organic colloids. To further characterize the nature of the Rio Negro colloids, the size distributions of the iron concentrations were determined by direct on-line coupling of the F-FFF to an inductively coupled plasma emission spectrometer (ICP-AES). The size distributions obtained by both F-FFF-UVA and F-FFF-ICP-AES were considerably smaller than expected from the stated pore size of the TFF membranes. These results demonstrate that care must be taken in using TFF to classify the size distribution of organic colloids and associated elements present in rivers. The iron distribution is more closely correlated to the organic matter distribution in the colloidal fraction than in the particulate fraction, but it is shifted towards heavier molecular weights for both fractions. The combination of electron paramagnetic resonance spectroscopy (EPR) and transmission electron microscopy (TEM) reveals the presence of iron occurring as: specific complexes with organic functional groups, as $\mathrm{Fe}-$ oxide/oxihydroxide phases, or as structurally incorporated component in kaolinite. Particulate and colloidal fractions are differentiated from each other with respect to the iron forms, which is in qualitative agreement with the F-FFF-ICPAES results.
\end{abstract}

(C) 2002 Published by Elsevier Science B.V.

Keywords: Colloid; Flow field-flow fractionation; Organic matter; Oxides; Iron; Speciation; Ultrafiltration EPR; TEM

\section{Introduction}

Despite its low concentration, colloidal material is recognized to play an important role in the fate of most elements in aquatic systems [1]. It may also

\footnotetext{
* Corresponding author. Tel.: +33-1-4427-5004; fax: +33-14427-5141.

E-mail address: benedett@cicrp.jussieu.fr (M.F. Benedetti).
}

control the bioavailability and mobility of most major and trace elements due to its high reactivity [1]. The environmental importance of colloidal organic matter and the various forms of colloidal iron has been characterized by a number of studies [2-5]. The Amazon River basin covers 6 million $\mathrm{km}^{2}$ and supplies up to $20 \%$ of all the river water discharged to the ocean [6]. Therefore, the Amazon River system is a prominent link in global carbon and metal ion cycles and understanding its 
aqueous geochemistry is of considerable importance. The suspended particulate matter was investigated in previous studies [4,7]. A limited number of papers investigates the role of colloids in the geochemistry of natural organic matter (NOM) and metal ions in the Amazon basin [812]. Moreover, the nature of colloids and their role in the Fe transport are still poorly documented [4]. The Rio Negro, a major tributary of the Amazon, is a significant contributor of colloidal carbon $(50-60 \%)$ and related metals such as $\mathrm{Fe}, \mathrm{Al}$ and Mn $[8,11,13]$.

Our aim in the present work is to gain additional insights into NOM properties and iron speciation in aquatic systems by using a combination of size fractionation by tangential-flow filtration (TFF), molecular weight characterization by flow fieldflow fractionation (F-FFF), spectroscopic, microscopic and physicochemical characterization of the colloidal material.

\section{Site and methods}

Two samples were collected in Brazil during the October 1998 cruise on the Rio Negro. This cruise corresponded to a falling stage period. The samples RNX (Lat.: S $0^{\circ} 14.14^{\prime}$ Long.: W $67^{\circ} 00.45^{\prime}$ ) and $\mathbf{J} 20$ (Lat.: S $3^{\circ} 04.14^{\prime}$ Long.: W 60 16.45') are taken in the upper part of the Rio Negro and before its mixing with the Amazon river, respectively (Fig. 1). Surface water samples were taken and processed on board with TFF (Ultrasart, Sartorius). All samples were treated in the same manner: 501 of water were filtered using clean ultrafiltration membranes with nominal cutoffs of $0.2 \mu \mathrm{m}$ and $5 \mathrm{kDa}$. All membranes were cleaned in the laboratory with 501 of Milli-Q water. In the field the first 51 were processed and discarded to prevent sample contamination during filtration (for detailed information on sampling and cleaning procedures see [10]). Concentration factors ranged from 8 to 15 . No attempt was made here to calibrate the ultrafiltration membrane, it is in this work a collection device [14-16]. Total organic carbon (TOC) was determined using a Shimadzu TOC analyzer that utilized a high temperature oxidation procedure prior to IR detection of $\mathrm{CO}_{2}$.
The detection limit was $0.1 \mathrm{mg} 1^{-1}$ and the precision ranged from 5 to $10 \%$.

Flow field-flow fractionation with UV absorbance detection (F-FFF-UVA), performed in 2000 at the Golden Colorado School of Mines (CO, USA) was used to investigate the molecular weight distributions of the recovered material. In the following discussion, the term colloid corresponds to entities with a size ranging from $1 \mu \mathrm{m}$ to a few $\mathrm{nm}$. The total colloidal fraction was subdivided into fraction $\mathrm{P}(1 \mu \mathrm{m}>\mathrm{P}>0.2 \mu \mathrm{m})$ and fraction $\mathrm{C}$ $(0.2 \mu \mathrm{m}>\mathrm{C}>5 \mathrm{kDa})$. F-FFF-UVA is an elution technique and the experimental arrangement of pump, F-FFF channel (Model F-1000, FFFractionation LLS, Salt Lake City, UT), and UV detector is similar to liquid chromatography. Only a brief description of F-FFF is included here, as both the theoretical basis and environmental applications of FFF have been described in detail elsewhere [17,18]. Flow FFF separations are carried out in a thin ribbon-like channel in which a laminar carrier flow, having a parabolic flow velocity distribution, is exposed to a perpendicular cross-flow field. Sample components interact with the field and are driven to the accumulation wall. Back-diffusion of sample components causes them to be distributed at characteristic heights above the channel wall. The diffusion coefficient establishes the average height of the center of mass of the sample 'cloud' and thus directly determines the average elution volume of sample components. NOM components are therefore primarily separated by molecular size. NOM components are detected as they elute from the F-FFF channel by UV absorbance at $254 \mathrm{~nm}$. The resulting plot of UV absorbance versus time or elution volume is termed the fractogram. F-FFF separation conditions were: channel flow $=0.5 \mathrm{ml} \mathrm{min}{ }^{-1}$, cross flow $=3.0 \mathrm{ml} \mathrm{min}{ }^{-1}$, carrier composition $0.01 \mathrm{M}$ $\mathrm{NaHCO}_{3}, 1 \mathrm{kDa}$ regenerated cellulose membrane (Amicon) and a $20 \mu \mathrm{l}$ sample injection loop. Triplicate F-FFF analyses were performed on the samples and the results averaged. Samples of reference humic substances, Suwannee River humic and fulvic acids, (IHSS standard reference collection) were also analyzed by F-FFF-UVA for comparison. Sample molecular weight $(M)$ distributions were obtained by calibration using glob- 


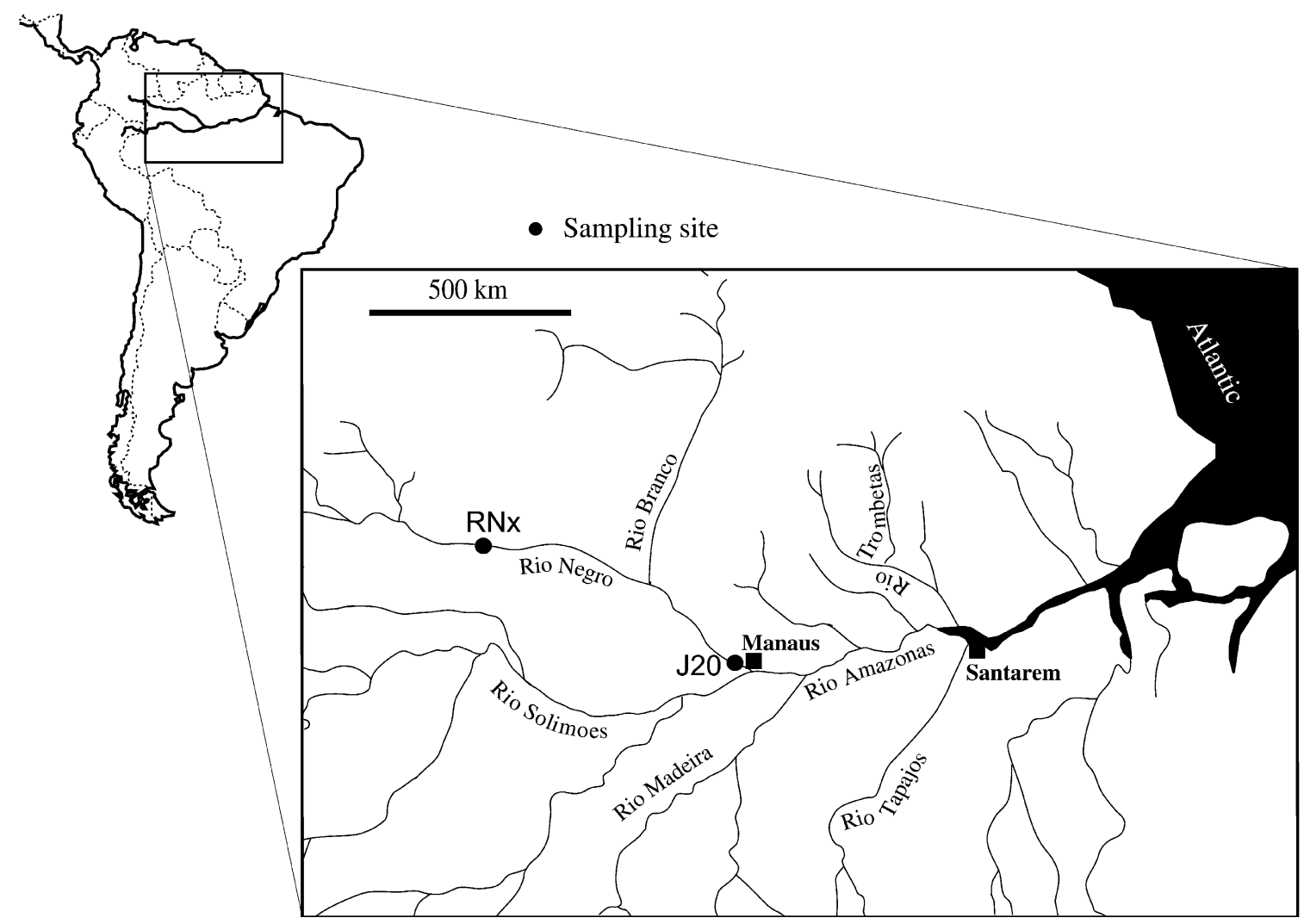

Fig. 1. Localization map of sampling points during the October 1998 cruise on the Rio Negro.

ular polystyrene sulfonate standards (PSS, American Polymer Standards) having molecular weights of $840,1430,4800,6500$ and $17500 \mathrm{Da}$. The calibration equation obtained relating $M$ and retention time $\left(t_{\mathrm{r}}\right)$ for these standards was:

$\log t_{\mathrm{r}}=0.367 \log M-0.391$

The conditions used to obtain fractograms for Fe concentrations were: channel flow $=0.8 \mathrm{ml}$

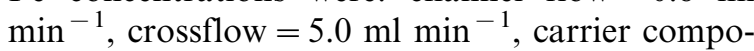
sition $0.001 \mathrm{M} \mathrm{NaCl}, 10 \mathrm{kDa}$ regenerated cellulose membrane (Amicon) and a $20 \mu \mathrm{l}$ sample injection loop. In this case the outlet from the UVA detector was connected directly to the ICP-AES (Perkin Elmer Optima 3000) using teflon tubing. Integration times were 5-10 s. An iron-containing solution was injected into the F-FFF channel with the cross field off to determine the time delay between the UVA and ICP-AES detectors.
Specific UV absorbance (SUVA), often considered a measure of the aromaticity of NOM, is defined here as the UV absorbance at $254 \mathrm{~nm}$ divided by TOC $\left(\mathrm{ng}^{-1}\right)$. The FFF detector was used at $254 \mathrm{~nm}$ but was not calibrated. However the integrated relative UV response of the fractograms were normalized to the sample TOC to allow use of the peak areas as a comparison of the relative 'colour' distribution, per $\mathrm{mg}$ of organic carbon, of each sample.

For electron paramagnetic resonance spectroscopy (EPR) and transmission electron microscopy (TEM) studies, the material was recovered later in the laboratory by centrifugation, operating at $35000 \times g\left(1 \mathrm{~h}\right.$ at $\left.20{ }^{\circ} \mathrm{C}\right)$ and $110000 \times g(17 \mathrm{~h}$ at $10{ }^{\circ} \mathrm{C}$ ) for $\mathrm{P}$ and $\mathrm{C}$ fractions, respectively. The materials in the supernatants of the $\mathrm{P}$ fraction (Ps) and of the $\mathrm{C}$ fraction (Cs) were recovered by centrifugation at $110000 \times g$ and by ultrafiltration at $5 \mathrm{kDa}$ with ultrafree Sartorius units, respec- 
tively. All fractions were then oven dried at $35{ }^{\circ} \mathrm{C}$ overnight. EPR measurements were performed at $9.42 \mathrm{GHz}$ (X-band) frequency with a Brucker ESP300E. The spectra were recorded at room temperature and at $145 \mathrm{~K}$, with a microwave power of $40 \mathrm{~mW}$, modulation amplitude of 3-5 gauss and normalized filling factor of the resonant cavity. Data were normalized according to gain and sample mass. Effective values of spectroscopic factor $g$ are calibrated with 1.1diphenyl-2picrylhydrazyl $(g=2.0037)$.

TEM experiments were carried out on a Jeol $2010 \mathrm{~F}$ microscope operating at $200 \mathrm{kV}$, equipped with a field emission gun, a high resolution UHR pole piece and a Gatan energy filter GIF 100. Images have been taken using elastically scattered electrons providing contrasted pictures of objects with low electron density such as organic particles. X-ray energy dispersive spectroscopy (XEDS) analyses were performed using a Kevex detector with an ultrathin window allowing detection of light elements. The preparation of samples for TEM observations was performed onboard according to the procedure described in [5], in order to fix the organo-mineral associations of riverborne particles. A drop of river water was mixed with hydrophilic resin, then spread over $\mathrm{Cu}$ grid by horizontal centrifugation, prior to polymerization in dessicator. No staining of samples was used.

\section{Results and discussion}

\subsection{F-FFF and iron distribution in the river samples}

For the Rio Negro, combined particulate and colloidal fractions account for at least $60 \%$ of the TOC $[8,11,13]$. Fe is found almost entirely $(99 \%)$ in fraction $P$ for all samples [19]. In the $0.2 \mu \mathrm{m}$ filtrate $80 \%$ of the $\mathrm{Fe}$ is located in the $\mathrm{C}$ fraction [19].

The molecular weight distributions for the standard humic substances and the organic samples are given in Fig. 2. Distributions have been normalized to the total UV area of each peak in order to allow comparison. Molecular weights smaller than $500 \mathrm{Da}$ are neglected in the calculated distributions. This is due to the unreliability of FFFF data in this small size range because of the

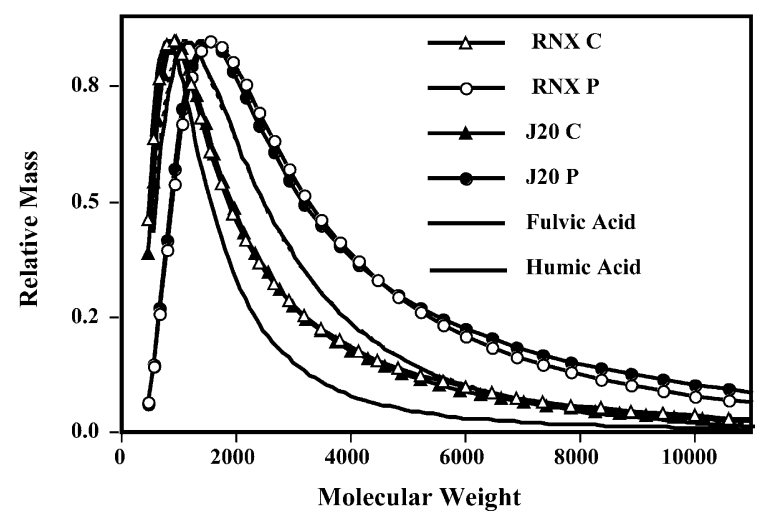

Fig. 2. Molecular weight (Da) distribution of IHSS standard humic substances and TFF isolated river colloids.

lack of resolution in F-FFF for molecules smaller than about $500-800 \mathrm{Da}$ and by the possible loss of the small sized colloids through the F-FFF membrane. Weight- and number-average molecular weights were computed and are presented in Table 1. The organic matter samples are, because of the TFF-defined molecular weights, operationally termed colloids. However, because of their low measured molecular weights, it could be argued that it is more appropriate to consider the organic matter in each TFF fraction as dissolved species.

The results in Fig. 2 show that the TFF isolates are intermediate in molecular weight distribution, lying between Suwannee River fulvic and humic acids. The particulate TFF isolates are considerably higher in molecular weight than Suwannee River humic acid. This result for the smallest TFF fraction, is consistent with the observation that riverine 'dissolved' NOM, from pedogenic origin, is usually composed of up to $70-80 \%$ fulvic acid as previously shown by [13] for other river samples from the Amazon basin taken in the past and at a different period of the hydrological year. The number average molecular weight $(\mathrm{Mn})$ result of $1160 \mathrm{Da}$ for the Suwannee River fulvic acid is in excellent agreement with previous FFF results $[20,21]$. The molecular weights of the two Rio Negro samples are nearly identical, suggesting uniform organic matter characteristics within the river. In contrast, other tributaries of the Amazon 
Table 1

Number (Mn) and Weight (Mw) average molecular weight and chemical composition of the different colloids

\begin{tabular}{|c|c|c|c|c|c|c|}
\hline Sample & $\mathrm{Mn}$ & Mw & $\mathrm{Fe}(\mathrm{ppm})$ & $\mathrm{Al}$ (ppm) & $\mathrm{Si}(\mathrm{ppm})$ & O.C. $\left(\mathrm{mg} \mathrm{l}^{-1}\right)$ \\
\hline FA & 1110 & 1660 & & & & \\
\hline HA & 1420 & 2270 & & & & \\
\hline RNX P UV & 1870 & 3330 & 4.26 & 3.59 & 1.7 & 104.3 \\
\hline RNX P fe & 2950 & 4820 & & & & \\
\hline RNX C UV & 1200 & 2250 & 7.66 & 5.28 & 2.06 & 342.3 \\
\hline RNX C fe & 1490 & 2810 & & & & \\
\hline J20 P UV & 1920 & 3910 & 18.8 & 20.3 & 20.16 & 143.1 \\
\hline J20 C UV & 1230 & 2350 & 7.19 & 4.30 & 3.63 & 265.4 \\
\hline
\end{tabular}

Results are based on UV or the Fe response for the recovered colloids.

examined in this study showed differences in molecular weight (manuscript in prep.). Although the molecular weights obtained by FFF for the TFF isolates are in the correct relative order $(\mathrm{P}>$ C) for each of the two samples, their values are considerably smaller than expected from the stated pore size of the TFF membranes even if they were not calibrated for the present study. Potential artefacts of tangential ultrafiltration have been systematically addressed [14-16] These results are consistent with the fact that other factors such as charge repulsion, concentration polarization on the membrane surface, and other experimental artifacts affect ultrafiltration as well as F-FFF results $[2,14-16,20]$. Random-coil PSS standards have previously been shown to better represent FFFF results for humic substances as compared to globular proteins [17]. Thus the molecular weights for the natural samples, obtained by F-FFF using PSS standards may be in more representative than the TFF molecular weight cutoff's obtained from protein standards. Present TFF results could be explained by the different hydrodynamic size to mass ratio of random-coil PSS and globular proteins used for calibration of ultrafiltration membranes. The observation that material retained by tangential-flow filtration is smaller than the stated pore-size had been made by others as well with calibrated membranes [22]. The presence of low molecular weight material in the particulate fraction could suggest that membrane fouling resulted in a reduction of the nominal molecular weight cutoff of the membranes. The low concentration factors used in this study could also explain the observed differences [14-16].

Fig. 3 shows the molecular weight distributions for the RNX sample of $\mathrm{Fe}$ signal along with UV response, which was normalized to the total peak areas to allow comparison. The iron response is shifted toward higher molecular weights fractions in the $\mathrm{P}$ fraction compared to the organic carbon response (UV). The same type of behavior is observed for fraction $\mathrm{C}$ but less markedly. Two possible explanations can account for this observation. The first one is that the affinity of the organic colloids for iron ions increases with their size. In other words the 'heavier' organic molecules would have a higher affinity binding constant for metal ions like Fe. This assumption is not supported by the lead titration experiments made on similar material made by [13] which show that the binding affinity does not vary with the size. However, for small tropical rivers colloids taken in the south of Brazil, [10] reports higher binding capacities with respect to copper for the high molecular weight fractions (i.e. fractions $>100$ $\mathrm{kDa}$ ). This could mean that lead is not the relevant metal ion to probe iron reactivity due to their different aquatic chemistry. The second explanation is that two different forms of iron may be present in both samples. The shift toward higher molecular weights could be due to the presence of a mineral form of iron. We have used EPR 

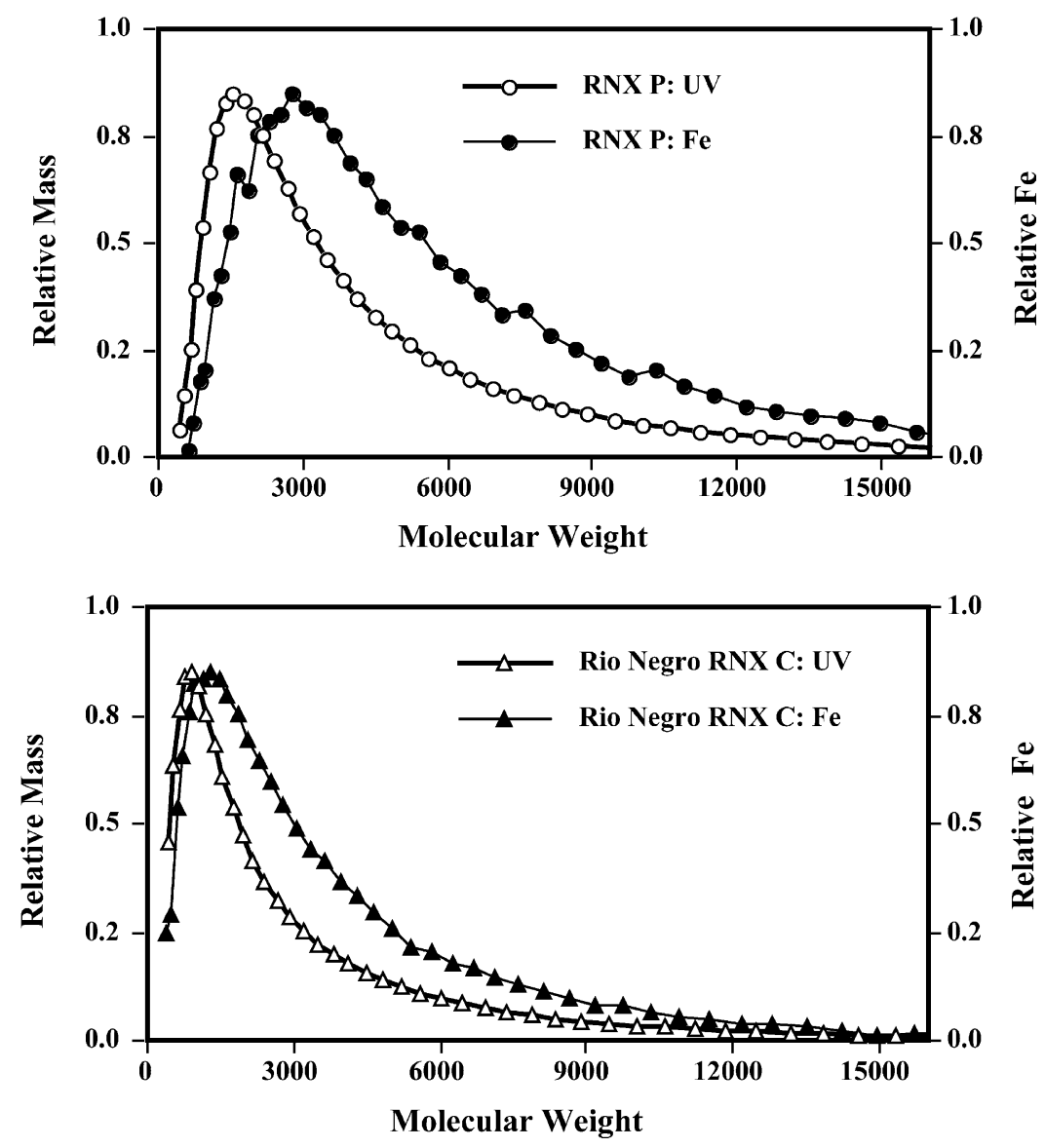

Fig. 3. Molecular weight (Da) distribution of UVA and Fe for TFF isolated river water fraction.

spectroscopic and TEM to identify the different forms of iron, as shown below.

\subsection{Paramagnetic species in river-borne solids}

The EPR spectra of fractions from the Rio Negro river are presented in Fig. 4. The observed species distinguish the fraction $\mathrm{P}$ from the others. The intense signals at low magnetic field (around 1500 gauss) arise from magnetically diluted $\mathrm{Fe}^{3+}$ in diamagnetic materials. In the $\mathrm{P}$ fraction, several resonances indicated in Fig. 3 characterize the axially-distorted signal of structural iron in kaolinite [[23] and reference therein]. They are superimposed to the rhombic signal at $g=4.3$ (around 1500 gauss) characteristic of $\mathrm{Fe}^{3+}$ bound to organic groups $\left(\mathrm{Fe}^{3+}-\mathrm{OM}\right)$ as inner sphere complex [[24], and reference therein]. This species is characteristic of the dominantly organic fractions Ps, C and Cs. Comparison with calibration data by [25] shows that trivalent iron complexed to organic matter is present at the weight percent level in these fractions.

In addition, the broad resonance ( $>1000$ gauss) centred in the 3300 gauss region arises from iron as oxides and oxi-hydroxides, irrespective of their actual composition and structure [26]. Both position of this signal and temperature dependence differentiate the $\mathrm{P}$ fraction from the other fractions. For Ps, C and Cs fraction, a decrease of amplitude of the broad resonance with decrease of temperature (not shown) was characteristic of a 


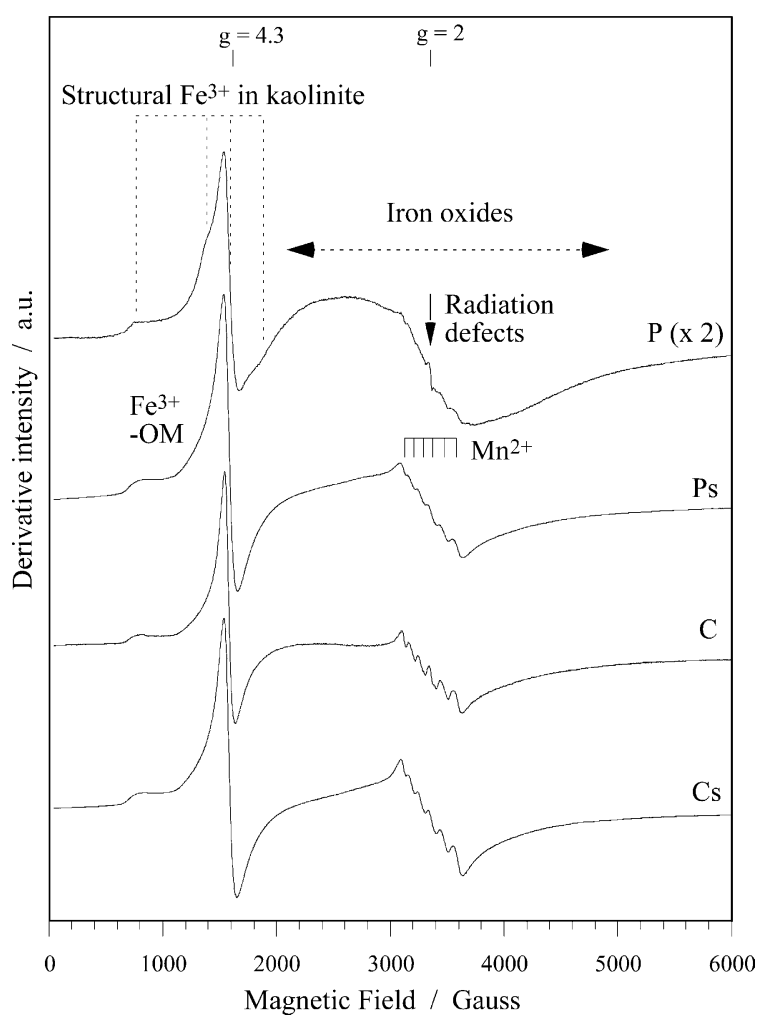

Fig. 4. EPR $(140 \mathrm{~K})$ of dried fractions of Rio Negro: particulate (centrifugate $\mathrm{P}$ and surpernatant $\mathrm{Ps}$ ) and colloidal (centrifugate $\mathrm{C}$ and surpernatant $\mathrm{Cs}$ ). Structural $\mathrm{Fe}^{3+}$ of kaolinite, $\mathrm{Fe}^{3+}$ complexed to organic matter $\left(\mathrm{Fe}^{3+}-\mathrm{OM}\right)$, divalent manganese, radiation-induced defects in kaolinite, and oxides sensu lato are identified. Dotted lines indicate main transitions of structural $\mathrm{Fe}^{3+}$ in kaolinite.

superparamagnetic behaviour and indicative of nanometric phases. In the $\mathrm{P}$ fraction, a reverse behaviour was observed, which may be due to the additional contribution of coarser oxide particles. Although not detailed in Fig. 4, a narrow and weak doublet was observed in the $\mathrm{P}$ fraction around 3300 gauss $(g=2$ region). Its $g$ components $\left(g_{/ /}=2.049\right.$ and $\left.g_{\perp}=2.007\right)$ are characteristic of radiation-induced defects accumulated in kaolinites from any environment [27]. The Rio Negro particles are also characterized by the presence of a six-line signal centred around $g=2$, which is due to hyperfine structure of $\mathrm{Mn}^{2+}$ ions, with a hyperfine constant $A \approx 96 \mathrm{G}$.

\subsection{Transmission electron microscopy}

Low magnification investigations have been carried out using a high defocus value and elastically scattered electrons. In such a way and owing to the coherence of the electron beam, weak phase object as organic matter are easily visible. Typical transmission electron microscopy observations of the raw Rio Negro water samples shown in Fig. 5 confirm the nature of major solid phases determined from XRD and FT-IR data obtained previously [4]. In addition to minerals occurring in the submicron size range (kaolinite, quartz), different forms of organic matter, with typical low electron density, are distinguished from their morphologies. Fibrils with a few nm width form network aggregates extending over hundreds of nanometers. They are characteristic of biopolymers released or derived from microorganisms. They correspond to a colloid class encountered in aquatic systems in variable proportions of the organic matter [3]. Occurring either in association with biopolymers or as isolated entities, unstructured gel-like domains of organic matter are also observed (Fig. 5(b)).

Colloidal, nanometric iron oxides in the broad sense are found associated with organic matter as biopolymer (Fig. 5(a)) and diffuse domains (Fig. 5(b)). This is in agreement with the observation of superparamagnetic phases by EPR in the Ps fraction. High resolution TEM brings into evidence the crystalline nature of these oxides (Fig. 5(c)). The direct observation of these colloids supports the identification of superparamagnetic phases revealed by EPR. In addition to iron and oxygen, XEDS analysis occasionally reveals the presence of associated silicon (Fig. 5). This association is frequent in colloidal iron oxides from freshwaters [5]. Moreover, both humics and silica may act as stabilizing agents for poorly ordered iron oxihydroxides such as ferrihydrites [28,29]. The association of nanometric iron oxides with organic matter is consistent with the relative charges of these compounds at the acidic $\mathrm{pH}$ of Rio Negro. Similar association was previously observed in organic-rich colloids from black waters of a tropical watershed in Cameroon [23]. 

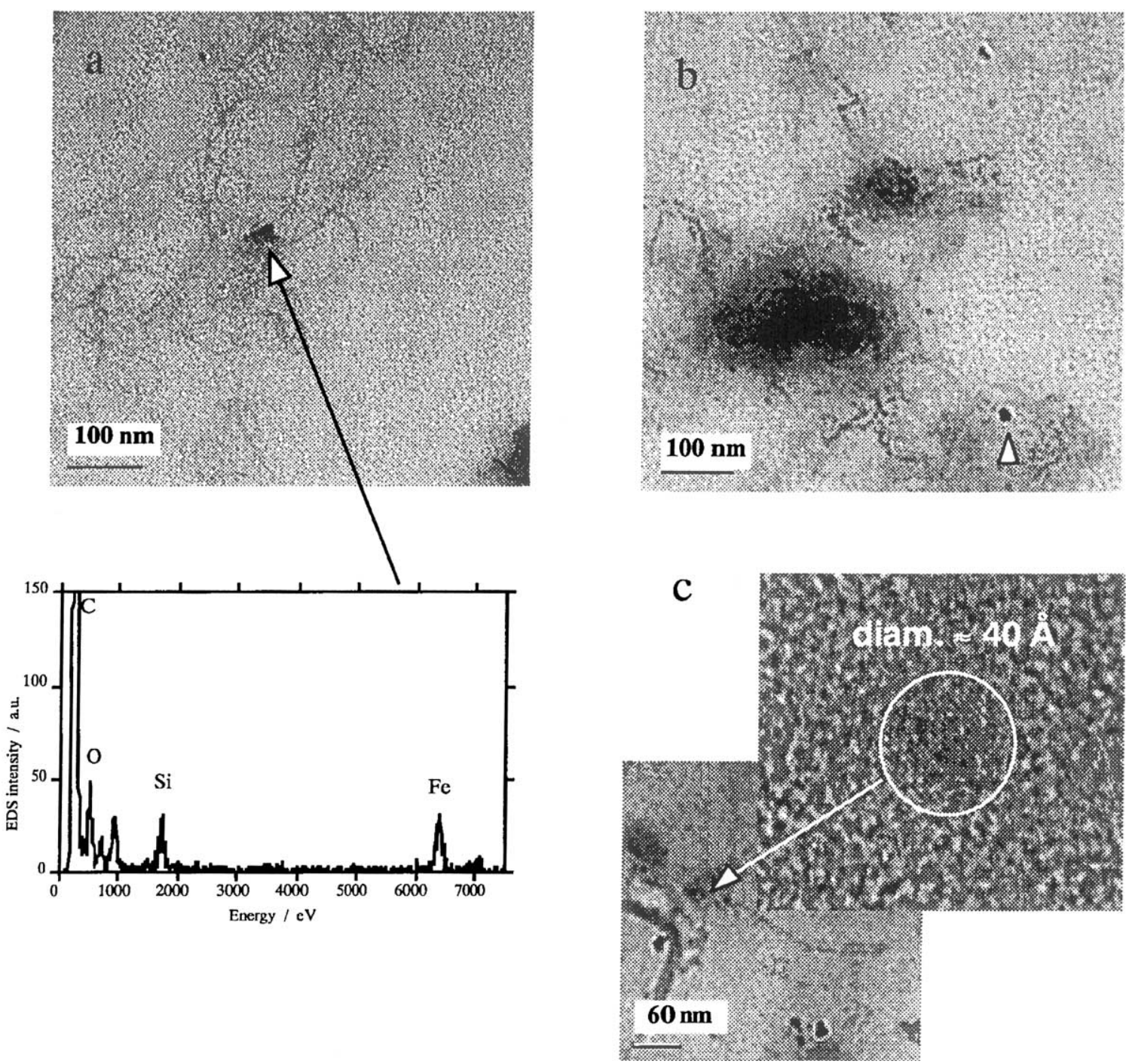

Fig. 5. TEM of colloids in Rio Negro river (unfiltered river sample). (a) Nanometric iron oxides (arrow) associated to network of organic biopolymers. Corresponding EDS spectrum. (b) Gel-like organic domains and iron oxides (arrow). (c) HRTEM of nanocristalline iron oxides (arrow).

\section{Acknowledgements}

This work was financially supported by Programme d'Etude de la Géosphère Intertropicale, PROgrame Sol et Erosion from the Institut des Sciences de l'Univers of the CNRS and the Institut de Recherche et Développement. The authors express their gratitude to the Hidrologia de Bacia Amazonica (CNPq-IRD-ANEEL and UnB) project team. The authors are also grateful for the use of the Jeol 2010F TEM provided by the Centre Pluridisciplinaire de Microscopie et de Microanalyse (CP2M) at the University of Aix-Marseille III. Access to the ICP-AES at CSM was provided by 
Dr Thomas Wildeman. Dr Ranville was partially supported In the work by an EPA grant (82665101-0).

\section{References}

[1] J. Buffle, Complexation Reactions in Aquatic Systems: An Analytical Approach, Ellis Norwood, Chichester, 1988, p. 692 ,

[2] J. Buffle, G.G. Leppard, Environ. Sci. Technol. 29 (1995) 2176.

[3] J. Buffle, K. Wilkinson, S. Stoll, M. Filella, J. Zhang, Environ. Sci. Technol. 32 (1998) 2887.

[4] Th. Allard, M. Ponthieu, T. Weber, N. Filizola, J.-L. Guyot, M.F. Benedetti, Bull. Soc. Géol. France 173 (2002) 67.

[5] D. Perret, J.-F. Gaillard, J. Dominik, O. Atteia, Environ. Sci. Technol. 34 (2000) 3540.

[6] M. Molinier, J.-L. Guyot, J. Callede, V. Guimaraes, E. Oliveira, N. Filizola, In: H. Thery (Ed.), Environnement et développement en Amazonie brésiliènne, Berlin, 1997, p. 24.

[7] G. Irion, In: E.T. Degens, S. Kempe, H. Soliman (Eds.), Transport of Carbon and Minerals in Major World Rivers. SCOPE/UNEP Sonderbd 55, 1983, pp. 482-504.

[8] I.L. Küchler, N. Miekeley, B.R. Forsberg, Sci. Total Environ. 156 (1994) 207.

[9] J.I. Hedges, G.L. Cowie, J.E. Richey, P.D. Quay, R.M. Benner, M. Strom, B.R. Forsberg, Limnol. Oceanogr. 39 (1994) 743.

[10] F. Eyrolle, M.F. Benedetti, J. Benaim, D. Fevrier, Geochim. Cosmochim. Acta 60 (1996) 3643.

[11] J. Benaïm, S. Mounier, Croatica Chim. Acta 71 (1998) 405.

[12] F. Gadel, L. Serve, M.F. Benedetti, L.C. Da Cunha, J.-L. Blazi, Agronomie 20 (2000) 477.
[13] M.F. Benedetti, J.F. Ranville, M. Ponthieu, J.P. Pinheiro, Organic Geochem. 33 (2002) 269.

[14] L. Guou, H.P. Santschi, Mar. Chem. 55 (1996) 113.

[15] L. Guou, B. Hunt, H.P. Santschi, Water Res. 35 (2001) 1500 .

[16] L. Guou, L.-S. Wen, D. Tang, H.P. Santschi, Mar. Chem. 69 (2000) 575.

[17] J.C. Giddings, in: M. Schimpf, K. Caldwell, J.C. Giddings (Eds.), Field Flow Fractionation Handbook, Wiley-Interscience, New York, 2000.

[18] R. Beckett, in: M. Schimpf, K. Caldwell, J.C. Giddings (Eds.), Field Flow Fractionation Handbook, Wiley-Interscience, New York, 2000.

[19] M.F. Benedetti, S. Mounier, N. Filizola, J. Benaim, P. Seyler, Hydrological Processes, in press.

[20] R. Beckett, J. Zue, J.C. Giddings, Environ. Sci. Technol. 28 (1987) 289.

[21] J.M. Dycus, K.D. Healy, G.K. Stearman, M.J.M. Wells, Sep. Sci. Technol. 30 (1995) 143.

[22] G. Newcombe, M. Drikas, S. Assemi, R. Beckett, Wat. Res. 31 (1997) 965.

[23] E. Balan, Th. Allard, B. Boizot, G. Morin, J.P. Muller, Clays Clay Miner. 47 (1999) 605.

[24] N. Senesi, In: D.C. Adriano (Ed.), Biogeochemistry of Trace Metals, Lewis Publishers, 1992, p. 429.

[25] G. Olivié-Lauquet, T. Allard, M.F. Benedetti, J.P. Muller, Wat. Res. 33 (1999) 2726.

[26] G. Olivié-Lauquet, Th. Allard, J. Bertaux, J.P. Muller, Chem. Geol. 170 (2000) 113.

[27] J.P. Muller, G. Calas, in: H.H. Murray, W. Bundy, C. Harvey (Eds.), Kaolin Genesis and Utilization, The Clay Minerals Society, Boulder, 1993, p. 261.

[28] U. Schwertmann, R.W. Fitzpatrick, Catena Suppl. 21 (1992) 7

[29] J.A. Leenheer, Acta Amazonica 10 (1980) 513. 